\title{
Recognition of Earthquake-Prone Areas in the Himalaya: Validity of the Results
}

\author{
A. Gorshkov, ${ }^{1}$ I. A. Parvez, ${ }^{2}$ and O. Novikova ${ }^{1}$ \\ ${ }^{1}$ Institute of Earthquake Prediction Theory and Mathematical Geophysics, Russian Academy of Sciences, Profsoyuznaya street 84/32, \\ 117997 Moscow, Russia \\ ${ }^{2}$ CSIR Centre for Mathematical Modelling and Computer Simulation (C-MMACS), NAL Belur Campus, Bangalore 560037, India
}

Correspondence should be addressed to A. Gorshkov, gorshkov@mitp.ru

Received 5 July 2012; Accepted 13 September 2012

Academic Editor: Rudolf A. Treumann

Copyright () 2012 A. Gorshkov et al. This is an open access article distributed under the Creative Commons Attribution License, which permits unrestricted use, distribution, and reproduction in any medium, provided the original work is properly cited.

\begin{abstract}
In 1992 seismogenic nodes prone for earthquakes 6.5+ have been recognized for the Himalayan arc using the pattern recognition approach. Since then four earthquakes of the target magnitudes occurred in the region. The paper discusses the correlation of the events occurred in the region after 1992 with nodes previously defined as having potential for the occurrence of earthquakes M6.5+. The analysis performed has shown that three out of four earthquakes M6.5+ occurred at recognized seismogenic nodes capable of M6.5+.
\end{abstract}

\section{Introduction}

Accurate definition of potential earthquake sources plays a main role on the development of seismic hazard assessment regardless of the applied methodology, either probabilistic or deterministic. In this paper, we analyze the results of the work by Bhatia et al. [1] dedicated to identification of earthquake-prone areas in the Himalaya. The work was carried out in 1992. Number of seismogenic nodes prone to M6.5+ have been defined in the region using pattern recognition approach $[2,3]$. This methodology is based on the idea that large earthquakes correlate with morphostructural nodes, specific structures formed at the intersections of fault zones. The fact that earthquakes nucleate at nodes was first established for the Pamirs and Tien Shan regions [2].The role of intersecting faults in the control of earthquake origin was later observed in different tectonic settings by other researchers. Specifically, Talwani $[4,5]$ found that large intraplate earthquakes are related to intersections and demonstrated that intersecting faults provide a location for stress accumulation. Hudnut et al. [6] and Girdler et al. [7] observed the relationship between earthquakes and intersections for plate boundaries and rift structures, respectively. According to King [8], fault intersections provide locations for initiation and healing of ruptures.
Apart from the Himalaya, seismogenic nodes for different target magnitudes have been previously recognized in many seismic regions of the world (e.g., [9-12]). After 1992 four earthquakes with $M \geq 6.5$ occurred in the Himalaya. The goal of this paper is to demonstrate how these events correlate with seismogenic nodes prone to M6.5+ defined in [1].

\section{Recognition of Seismogenic Nodes in the Himalaya}

In this section we briefly introduce the basic postulates of the methodology used by Bhatia et al. [1] for identification of earthquake-prone areas in the Himalaya.

The methodology includes two main steps. The first step is the determination of the morphostructural nodes to be regarded as recognition patterns, using the MZ method [3]. The second step is the classification of all mapped nodes into nodes where earthquakes with magnitude exceeding a certain threshold $\left(M_{0}\right)$ are possible and nodes where only earthquakes with smaller magnitude may happen, using the pattern recognition algorithms CORA-3 $[3,10]$.

At the first stagethe study region is divided into a system of hierarchically ordered areas characterized by homogeneous present-day topography and tectonic structure. MZ 


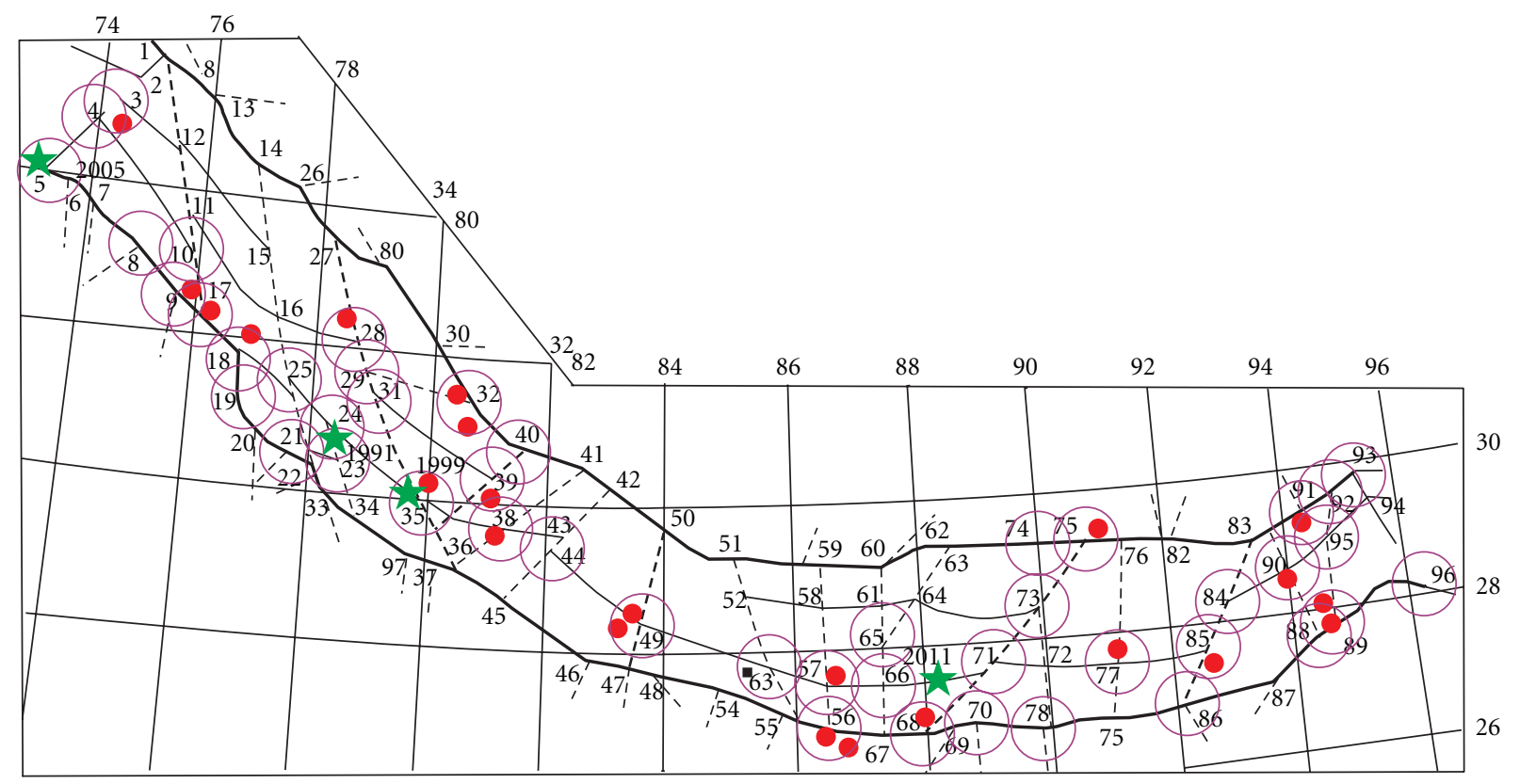

FIGURE 1: Himalaya: MZ map, seismogenic nodes for M6.5+, and post-publication earthquakes M6.5+.

distinguishes (1) areas of different rank, called blocks; (2) their boundary zones, called morphostructural lineaments; (3) sites where lineaments intersect, called nodes. The MZ map of the Himalaya, shown in Figure 1, has been compiled using topographic, geologic, and tectonic maps and satellite images. In every detail the map is described in [1]. In total, MZ delineated 97 lineament intersections and each of them was threaten as a node.

The use of the pattern recognition approach suggests that nodes already marked by one or more strong earthquakes might have a similar portrayal that can be used to identify nodes, which did not yet explicitly show up as earthquake prone. The goal of the recognition is to classify all the nodes delineated within a region into two classes:

(1) class D containing the nodes where earthquakes with magnitude $M \geq M_{0}$ may occur;

(2) class $\mathbf{N}$ containing the nodes where only earthquakes with $M<M_{0}$ may occur.

The goal of recognition in the Himalaya was to separate nodes into two classes: the nodes where earthquakes with magnitude $M \geq 6.5$ may occur (class $\mathrm{D}$ ) and those where only earthquakes with $M<6.5$ may occur (class $\mathbf{N}$ ). Using the information on the recorded earthquakes M6.5+, two sample sets of nodes were selected: $\mathbf{D}_{0}$ representing class $\mathbf{D}$ and $\mathbf{N}_{0}$ representing class $\mathbf{N}$. Each node was described by the topographical, geological, and geomorphological parameters. The values of the parameters form a vector that is associated with a node. The vectors were classified into classes $\mathbf{D}$ and $\mathbf{N}$ using pattern recognition techniques, specifically the CORA-3 algorithm $[3,10]$ that operates in two stages. At the learning stage the algorithm selects the characteristic $\mathbf{D}$ - and $\mathbf{N}$-traits for classes $\mathbf{D}$ and $\mathbf{N}$, using samples $\mathbf{D}_{0}$ and $\mathbf{N}_{0}$. At the classification stage the algorithm counts the numbers of $\mathbf{D}$ - and $\mathbf{N}$-traits that each node possesses and assigns each node to one of the two classes, in accordance with the number of prevailing traits.

2.1. Earthquake-Prone Areas in the Himalaya. The nodes prone to M6.5+ have been determined using pattern recognition technique.

2.1.1. Parameters Used for Recognition. Nodes were characterized by a set of topographical and geological parameters as well as parameters of lineament-and-block geometry of the region shown in Figure 1. The parameters used are presented in Table 1. The parameters describing the topographic altitudes and the area of soft sediments (Table 1) characterize indirectly the contrast and intensity of the present-day tectonic movements, while those describing the density of lineaments can be related to the degree of crust fragmentation and heterogeneity.

The CORA-3 pattern recognition algorithm, used for identification of seismogenic nodes in the Himalaya, operates in a binary vector space. Therefore the values of the parameters were transformed into binary vector space by discretization and coding. This was made by dividing each parameter range into two parts by means of a threshold of discretization. After the discretization, the values of the parameters are converted into binary components with the value 1 ("small") or 0 ("large") depending on which interval the value belongs to. The thresholds of discretization for parameters are presented in Table 1 . A vector of values of these parameters represents each node. The set of these vectors is the input for the recognition algorithms.

Thick lines are the lineaments of the first rank, medium lines are the lineaments of the second rank, thin lines are the lineaments of the third rank, continues lines are the 
TABLE 1: Parameters used for recognition and their thresholds of discretization.

\begin{tabular}{|c|c|}
\hline Parameters & $\begin{array}{l}\text { Thresholds of } \\
\text { discretization }\end{array}$ \\
\hline \multicolumn{2}{|l|}{ Topographic parameters } \\
\hline Minimum topographic altitude, $\mathrm{m}\left(H_{\min }\right)$ & $\leq 300>2100$ \\
\hline Relief energy, $\mathrm{m}(\Delta H)\left(H_{\max }-H_{\min }\right)$ & $\leq 2900>4400$ \\
\hline \multicolumn{2}{|l|}{$\begin{array}{l}\text { Distance between the points where } H_{\max } \text { and } \\
H_{\min } \text { are measured, } \mathrm{km}(L)\end{array}$} \\
\hline Slope, $(\Delta H / L)$ & $\leq 40>70$ \\
\hline \multicolumn{2}{|l|}{ Parameters from the morphostructural map } \\
\hline $\begin{array}{l}\text { Distance to the nearest } 2 \mathrm{nd} \text { rank lineament, } \\
\mathrm{km},\left(D_{2}\right)\end{array}$ & $\leq 50>120$ \\
\hline $\begin{array}{l}\text { Distance to the nearest intersection out of this } \\
\text { node, } \mathrm{km},\left(D_{\text {int }}\right)\end{array}$ & $\leq 50>62$ \\
\hline Morphological parameter & - \\
\hline \multicolumn{2}{|l|}{$\begin{array}{l}\text { This parameter takes one of the following } \\
\text { three values in accordance with the contact of } \\
\text { relief types in the node: } \\
\text { Mountain/plain }(\mathrm{m} / \mathrm{p})\end{array}$} \\
\hline \multicolumn{2}{|l|}{ Mountain/piedmont/plain (m/pd/p) } \\
\hline \multicolumn{2}{|l|}{ Mountain/piedmont $(\mathrm{m} / \mathrm{pd} /)$} \\
\hline \multicolumn{2}{|l|}{ Mountain/upland (m/up) } \\
\hline Mountain/mountain $(\mathrm{m} / \mathrm{m})$ & \\
\hline
\end{tabular}

longitudinal lineaments, and discontinuous ones are the transverse lineaments. Circles are $\mathbf{D}$ nodes prone to $M \geq$ 6.5 events; noncircled intersections of the lineaments are $\mathbf{N}$ nodes. Black dots denote epicenters of earthquakes with $M \geq$ 6 before 1992. Stars show earthquakes M6.5+ occurred after 1992. Small Roman numerals indicate numbers of nodes.

2.1.2. Nodes and Earthquakes M6.5+. In the Himalaya pattern recognition technique has been applied to find nodes prone to M6.5+. To select the sample nodes for the learning stage of the recognition, the information on the recorded events with M6.5+ has been taken from the NEIC and Indian Meteorological Department Catalogues. 23 earthquakes, plotted in Figure 1, were selected from these catalogues. As Figure 1 shows, the epicenters of the earthquakes considered are located near the intersection of lineaments, that is, at the nodes. The distance between the epicenters and the points of intersection does not exceed $30 \mathrm{~km}$. The recorded earthquakes nucleate at the nodes, thus it is possible to apply pattern recognition for the node classification.

2.1.3. Selection of the Training Sets for the CORA-3 Algorithm. At the learning stage all the nodes are a priori divided into three sets. The nodes situated most closely to the epicenters composed training set $\mathbf{D}_{0}$ for class $\mathbf{D}$. On the contrary, training set $\mathbf{N}_{0}$ for class $\mathbf{N}$ included the nodes that are most distant from the epicenters. At some of the nodes earthquakes with $6.0 \leq M \leq 6.4$ were known at the moment of recognition. These nodes were assigned to the set $\mathbf{X}$ that
TABle 2: Characteristic D-features and $\mathbf{N}$-features of nodes for $\mathrm{M} 6.5+$.

\begin{tabular}{|c|c|c|c|c|c|c|}
\hline \multirow{2}{*}{ No } & \multicolumn{6}{|c|}{ Parameters } \\
\hline & $\begin{array}{l}\text { Combination } \\
\text { of landforms }\end{array}$ & $D_{\text {int }}, \mathrm{km}$ & $D_{2} \mathrm{~km}$ & $\Delta H, \mathrm{~m}$ & $\Delta H / L$ & $H_{\min }, \mathrm{m}$ \\
\hline \multicolumn{7}{|c|}{ D-features } \\
\hline 1 & & & & & 70 & $300-2100$ \\
\hline 2 & & & $\leq 50$ & & & $300-2100$ \\
\hline 3 & & & $\leq 120$ & & 70 & $\leq 2100$ \\
\hline 4 & & & $>120$ & & $\leq 70$ & $\leq 2100$ \\
\hline 5 & $\begin{array}{c}\mathrm{m} / \mathrm{p} \text { or } \\
\mathrm{m} / \mathrm{pd} / \mathrm{p} \text { or } \\
\mathrm{m} / \mathrm{pd}\end{array}$ & & & & $>40$ & \\
\hline 6 & & & $\leq 50$ & & $>40$ & $\leq 2100$ \\
\hline 7 & & & $\leq 50$ & & $>70$ & \\
\hline 8 & & $\leq 62$ & $\leq 50$ & & & $>300$ \\
\hline 9 & & $\leq 62$ & $\leq 50$ & & $>40$ & \\
\hline 10 & & $\leq 62$ & $\leq 120$ & $>4400$ & & \\
\hline 11 & & $>50$ & $>50$ & $>4400$ & & \\
\hline 12 & & $50-62$ & & $>4400$ & & \\
\hline \multicolumn{7}{|c|}{$\mathrm{N}$-features } \\
\hline 1 & & & & & $\leq 70$ & $>2100$ \\
\hline 2 & & & $>50$ & & & $>2100$ \\
\hline 3 & & & & $<2900$ & $\leq 40$ & \\
\hline 4 & & & $\leq 120$ & & $\leq 40$ & \\
\hline 5 & & $>50$ & & & $\leq 40$ & \\
\hline 6 & & $>50$ & & $\leq 2900$ & $\leq 70$ & \\
\hline 7 & $\begin{array}{c}\text { Not } \mathrm{m} / \mathrm{p} \text { or } \\
\mathrm{m} / \mathrm{pd} / \mathrm{p}\end{array}$ & & $>120$ & & $>40$ & \\
\hline 8 & $\mathrm{~m} / \mathrm{m}$ or $\mathrm{m} / \mathrm{up}$ & & $>50$ & $\leq 4400$ & & \\
\hline 9 & $\mathrm{~m} / \mathrm{m}$ or $\mathrm{m} / \mathrm{up}$ & & $>120$ & & & \\
\hline
\end{tabular}

was not employed for the selection of the characteristic traits; the nodes from the set $\mathbf{X}$ were classified at the recognition stage.

2.1.4. Recognition of Nodes Prone to M6.5+. The classification has been obtained with the following values of the parameters of CORA-3 algorithm [3]: $k_{1}=5, \bar{k}_{1}=6, k_{2}=16$, and $\bar{k}_{2}=1$. At the learning stage $12 \mathrm{D}$-traits and nine $\mathbf{N}$-traits (Table 2) were selected by algorithm.

At the classification stage, for each object, the numbers of $\mathbf{D}\left(n_{\mathbf{D}}\right)$ - and $\mathbf{N}$-traits $n_{\mathbf{N}}$ that it possesses were calculated. The class $\mathrm{D}$ is formed by the objects with $n_{\mathrm{D}}>n_{\mathrm{N}}$. As a result, all 21 nodes originally from $\mathbf{D}_{0}$, three nodes $(10,71$, 86) from $\mathbf{X}$, and 24 nodes from the set $\mathbf{N}_{0}$ were assigned to class D.In total, 48 nodes among 97 , delineated by MZ in the Himalaya, were recognized as potential for the occurrence of earthquakes M6.5+. Their locations are shown in Figure 1.

The stability of the resulting classification has been proved by satisfactory results of a number of the control tests described in [3]. 
TABLe 3: Post-publication events and their correlation with nodes.

\begin{tabular}{lccccc}
\hline Date & Epicenter & Depth & $M$ & Difference $\Delta I_{0}$ & Node type \\
\hline $1991 / 10 / 19$ & 30.78 N 78.77E & 10 & 7.0 & 0.5 & Node $\mathbf{D}^{*}$ \\
$1999 / 03 / 28$ & $30.51 \mathrm{~N} 79.40 \mathrm{E}$ & 15 & 6.6 & 0.2 & Node D \\
$2005 / 08 / 10$ & $34.54 \mathrm{~N} 73.59 \mathrm{E}$ & 26 & 7.6 & 2.3 & Node D* \\
$2011 / 09 / 18$ & $27.72 \mathrm{~N} 8814 \mathrm{E}$ & 50 & 6.9 & 0.8 & Outside nodes \\
\hline
\end{tabular}

Note: $\mathbf{D}^{*}$ indicates nodes where at the time of recognition earthquakes M6.5+ were unknown.

\section{Nodes Prone to M6.5+ and Postpublication Earthquakes}

Table 2 presents the characteristic features that discriminate $\mathbf{D}$ nodes from $\mathbf{N}$ nodes in the Himalaya. Potential (D) nodes are characterized by their small distances to secondrank lineaments $\left(D_{2} \leq 50 \mathrm{~km}\right)$ and small distances to the nearest intersection $\left(D_{\text {int }} \leq 62 \mathrm{~km}\right)$. Additionally, $\mathbf{D}$ nodes exhibit a "large" difference in altitudes $(\Delta H>4400 \mathrm{~m})$, "large" values of topography gradient $(\Delta H / L>40)$, and "small" values" of minimum topographic altitude $\left(H_{\min } \leq\right.$ $2100 \mathrm{~m}$ ). Besides, combinations of contrasting landforms such as mountain slope/piedmont plains and mountain slope/piedmont hills/piedmont plains are predominant features of D nodes. Such set of characteristic features of D nodes indicate a high degree of the crust fragmentation and intense neotectonic movements in the vicinity of these nodes. Criteria of nompotential $(\mathbf{N})$ nodes reveal a lesser degree of tectonic activity around $\mathrm{N}$ nodes.

After 1992 four earthquakes M6.5+ occurred in the Himalaya. Figure 1 shows locations of the events. Table 3 presents parameters of these events and their correlation with nodes. Table 3 also introduces the difference between observed $I_{0}$ for each event and $I_{0}$ shown on the GSHAP map for the zone where each of considered events occurred. The difference was calculated with the method proposed by Kossobokov and Nekrasova [13]. Table 3 shows that the high seismic potential of node no. 5, where the 2005 Muzaffarabad earthquake took place, was estimated by pattern recognition more adequately as compared with the GSHAP data. Seismic potential of the area of the 2005 Muzzafarabad earthquake is underestimated by the probabilistic GSHAP approach.

We included in the analysis the 1991 Uttarkashi earthquake because it happened when the work by Bhatia et al. [1] was already finished and this event was not used at the learning stage of recognition. The Uttarkashi earthquake occurred at node no. 24 where earthquakes of target magnitudes were unknown during pattern recognition. The 1999 Chamoli earthquake occurred at the recognized D nodes no. 35 that was used at the learning stage of pattern recognition. The devastating 2005 Muzzafarabad earthquake correlates with D node no. 5. The 2011 Sikkim earthquake occurred between two D nodes no. 66 and no. 71 at the distance of $70 \mathrm{~km}$ from D node no. 66. The epicenter of this event clearly correlates with the second-rank lineament.

Finally, the analysis performed shows that three out of four postpublication earthquakes confirm the results of recognition obtained by Bhatia et al. [1]. Therefore, we can conclude that the pattern recognition approach applied for earthquake-prone areas identification provides sufficiently reliable information to be used for seismic hazard research.

\section{Acknowledgment}

The research has been supported by the RFBR-DST Grants no. 11-05-92691 and 12-05-92699.

\section{References}

[1] S. C. Bhatia, T. R. K. Chetty, M. B. Filimonov, A. I. Gorshkov, E. Y. Rantsman, and M. N. Rao, "Identification of potential areas for the occurrence of strong earthquakes in Himalayan arc region," Proceedings of the Indian Academy of SciencesEarth and Planetary Sciences, vol. 101, no. 4, pp. 369-385, 1992.

[2] I. M. Gelfand, S. I. Guberman, M. L. Izvekova, V. I. KeilisBorok, and E. J. Ranzman, "Criteria of high seismicity, determined by pattern recognition," Tectonophysics, vol. 13, no. 1-4, pp. 415-422, 1972.

[3] A. Gorshkov, V. Kossobokov, and A. Soloviev, "Recognition of earthquake-prone areas," in Nonlinear Dynamics of the Lithosphere and Earthquake Prediction, V. Keilis-Borok and A. Soloviev, Eds., pp. 239-310, Springer, Heidelberg, Germany, 2003.

[4] P. Talwani, "The intersection model for intraplate earthquakes," Seismological Research Letters, vol. 59, no. 4, pp. 305310, 1988.

[5] P. Talwani, "Fault geometry and earthquakes in continental interiors," Tectonophysics, vol. 305, no. 1-3, pp. 371-379, 1999.

[6] K. W. Hudnut, L. Seeber, and J. Pacheco, "Cross-fault triggering in the November 1987 Superstition Hills earthquake sequence, Southern California," Geophysical Research Letters, vol. 16, no. 2, pp. 199-202, 1989.

[7] R. W. Girdler and D. A. McConnell, "The 1990 to 1991 Sudan earthquake sequence and the extent of the East African rift system," Science, vol. 264, no. 5155, pp. 67-70, 1994.

[8] G. C. P. King, "Speculations on the geometry of the initiation and termination processes of earthquake rupture and its relation to morphology and geological structure," Pure and Applied Geophysics, vol. 124, no. 3, pp. 567-585, 1986.

[9] A. Cisternas, P. Godefroy, A. Gvishiani et al., "1985 A dual approach to recognition of earthquake prone areas in the Western Alps," Annales Geophysicae, vol. 3, no. 2, pp. 249-270.

[10] I. M. Gelfand, S. A. Guberman, V. I. Keilis-Borok et al., "Pattern recognition applied to earthquake epicenters in California," Physics of the Earth and Planetary Interiors, vol. 11, no. 3, pp. 227-283, 1976.

[11] A. I. Gorshkov, G. F. Panza, A. A. Soloviev, and A. Aoudia, "Identification of seismogenic nodes in the Alps and Dinarides," Bollettino della Società Geologica Italiana, vol. 123, pp. 3-18, 2004. 
[12] A. I. Gorshkov, A. A. Soloviev, M. J. Jiménez, M. GarcíaFernández, and G. F. Panza, "Recognition of earthquake-prone areas $(\mathrm{M} \geq 5.0)$ in the Iberian Peninsula," Rendiconti Lincei, vol. 21, no. 2, pp. 131-162, 2010.

[13] V. G. Kossobokov and A. K. Nekrasova, "Global seismic hazard assessment program maps are erroneous," Seismic Instruments, vol. 48, no. 2, pp. 162-170, 2012. 

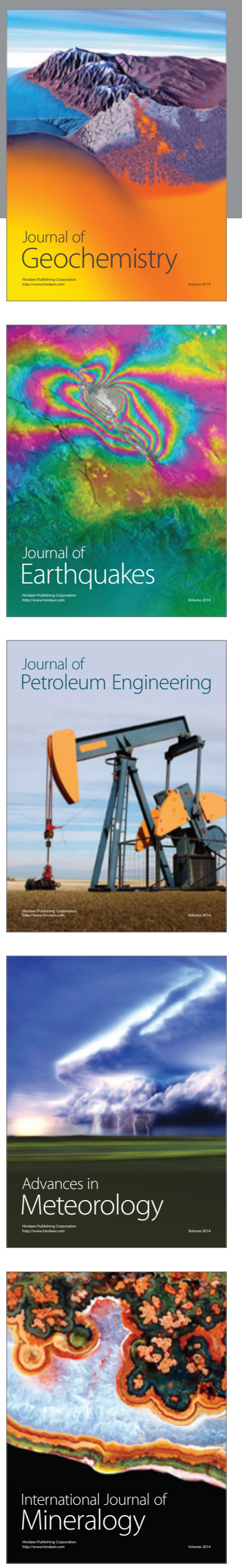
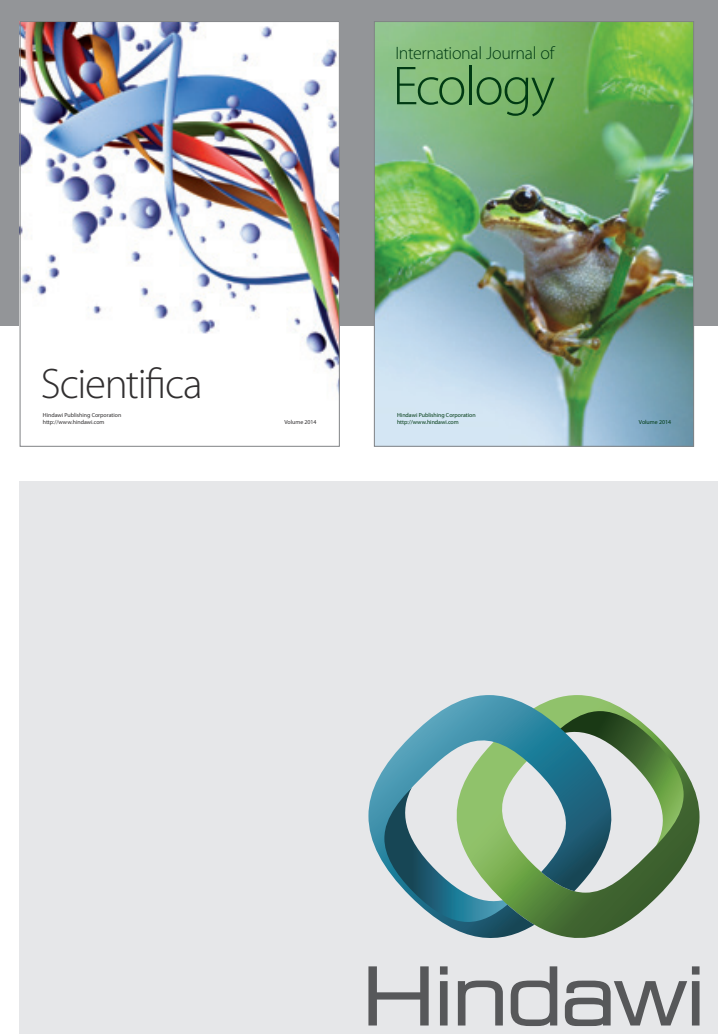

Submit your manuscripts at http://www.hindawi.com
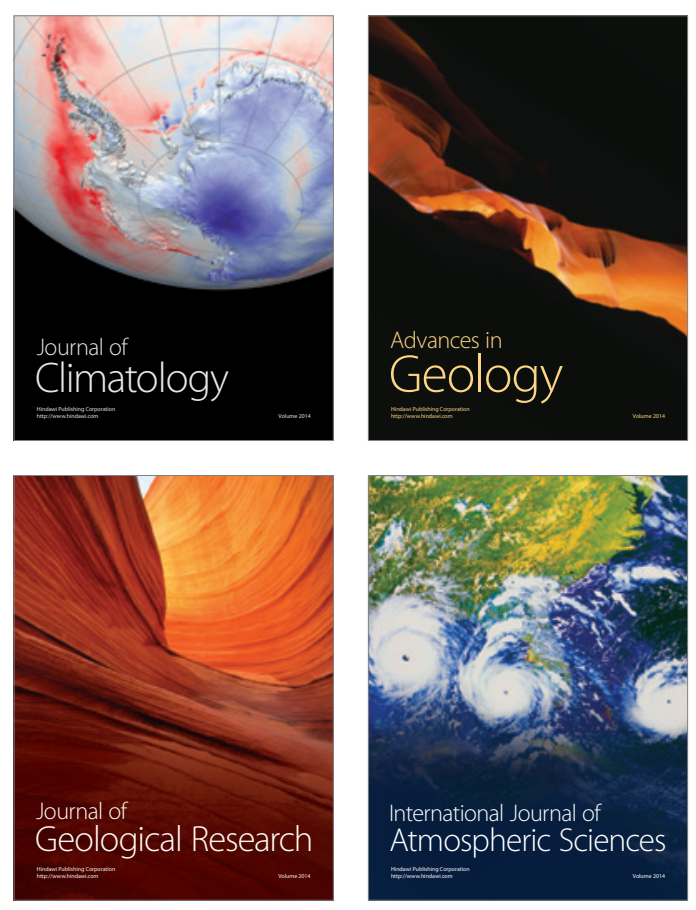
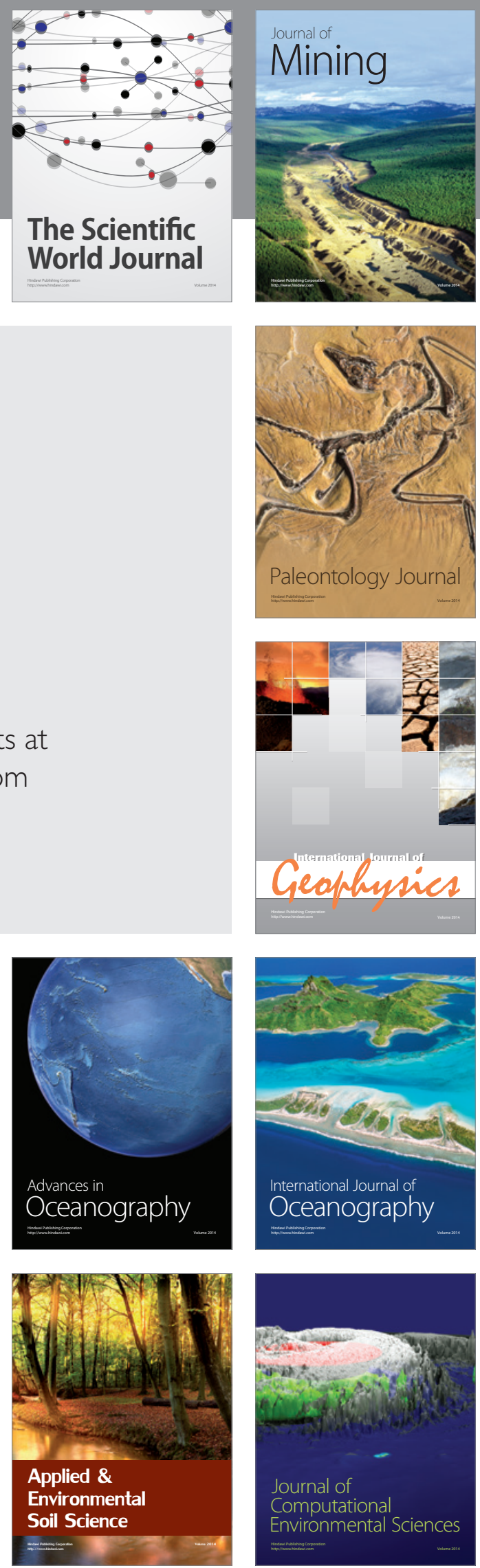